\title{
Study on the Interaction between Low-Viscosity High-Permeability Pregrouting Sealing Material and Coal and Its Application
}

\author{
Yujia Chen, ${ }^{1,2,3}$ Ao Li $\mathbb{D},{ }^{4,5}$ Dingding Yang $\mathbb{D}^{6},{ }^{6}$ Tianyu Liu, ${ }^{1,2,3}$ Xiaowei Li $\mathbb{D},{ }^{1,2,3}$ \\ Jun Tang, ${ }^{1,2,3}$ and Chenglin Jiang ${ }^{1,2,3}$ \\ ${ }^{1}$ Key Laboratory of Gas and Fire Control for Coal Mines, Xuzhou 221116, Jiangsu, China \\ ${ }^{2}$ National Engineering Research Center of Coal Gas Control, Xuzhou 221116, Jiangsu, China \\ ${ }^{3}$ School of Safety Engineering, China University of Mining \& Technology, Xuzhou 221116, Jiangsu, China \\ ${ }^{4}$ College of Safety and Emergency Management Engineering, Taiyuan University of Technology, Taiyuan 030024, Shanxi, China \\ ${ }^{5}$ Jiangsu Vocational Institute of Architectural Technology, Xuzhou 221000, Jiangsu, China \\ ${ }^{6}$ School of Petrochemical and Energy Engineering, Zhejiang Ocean University, Zhoushan 316022, Zhejiang, China \\ Correspondence should be addressed to Ao Li; everliao@gmail.com
}

Received 19 August 2019; Accepted 25 September 2019; Published 12 February 2020

Guest Editor: Ruiyu Jiang

Copyright (c) 2020 Yujia Chen et al. This is an open access article distributed under the Creative Commons Attribution License, which permits unrestricted use, distribution, and reproduction in any medium, provided the original work is properly cited.

\begin{abstract}
In order to ensure the intactness of pressure-measuring boreholes and the accuracy of gas pressure determination, pregrouting treatment with polymer materials is frequently applied to bedding drilling in coal mines. However, the existing polyurethane materials are of high viscosity, low permeability, and poor safety, bringing great difficulties to their field promotion and application. In view of this problem, after optimization and experiments, polylactide polyol/polyether polyol $4110 /$ isocyanate was determined as the target system. Bio-based benzoxazine (Boz-F), red phosphorus, and melamine with a mass ratio of $2: 1: 2$ were used as the flame retardant, which then underwent mechanical modification by hollow glass bubbles. Finally, the pregrouting material with low viscosity and high permeability was compounded, and its interaction with coal was experimentally studied. The results show that compared with traditional polyurethane, the new material increases the effective consolidation distance in the coal seam by $40 \%$ on average. Its permeation radius is also larger than the calculated radius of the plastic softening zone of a borehole. In addition, the strengths of coal-new material consolidated products with different ratios fully surpass those of coalpolyurethane material consolidated products. The enhancement of compressive strength and bending strength is up to $153 \%$ and $161 \%$, respectively. The field application indicates that after pregrouting treatment of boreholes in the coal seam with the new material, the borehole formation rate reaches $100 \%$. Therefore, the new material is safe and practical for gas pressure measurement through bedding drilling on site.
\end{abstract}

\section{Introduction}

With the development of national economy, more and more polymer materials have been applied to the coal industry [1-6]. As far as gas prevention and control is concerned, polymer materials are more and more frequently applied to mine gas pressure measurement. The utilization of polyurethane as a sealing material for bedding drilling during gas pressure measurement is a practical method developed in recent years. On the one hand, polyurethane materials can consolidate the loose coal layers around bedding boreholes
[7-10]. On the other hand, it can seal coal fractures [11-14], thus creating good conditions for the pressure measurement [15-17]. However, practical applications have revealed that the raw polyurethane material is of high viscosity and poor permeability into coal. If a high injection pressure is applied, it will migrate along cracks of a loose layer to a rather far place so that it cannot effectively reinforce the loose layer surrounding a borehole. In addition, it has poor safety performance characterized by problems such as high temperature in the consolidation process and poor flame retardancy. Mine fires caused by polymer materials occur 
from time to time, which severely limits the application of polyurethane materials to mines. Hence, it is necessary to develop a new type of low-viscosity and high-permeability sealing material. First, the new material should feature low viscosity. That is, it should have better permeability than polyurethane materials under normal or lower pressures, because high permeability enables it to bond with coal in a large range to consolidate loose layers. Second, it should feature a suitable consolidation time for the material to be injected into the coal seam. Finally, it should boast good safety performance, namely low consolidation temperature and high flame-retardant grade, so as to guarantee its safe application to the coal industry. A new material with these characteristics can better permeate fractures in a coal seam, seal cracks, and bond the coal, thus meeting the practical need of gas pressure measurement through bedding drilling.

To achieve the aforesaid objectives, polylactide polyol/ polyethylene/glycol 200/polyethylene glycol 600, polyether polyol 4110, and isocyanate were used as main raw materials to compound three kinds of composites. After optimization, polylactide polyol/polyether polyol 4110/isocyanate was determined to be the target system (basic formula). It was found that with the addition of polylactide polyol, the peak temperature of the new material in the consolidation process declined, and the consolidation time was prolonged. Without affecting foaming performance of the material, the optimal mass ratio of polylactide polyol: polyether polyol 4110 : isocyanate was finally determined to be $4: 6: 10$ (i.e., 2 : $3: 5$ ). The basic formula was used for the subsequent research. Furthermore, an analysis was conducted on the lowtemperature consolidation mechanism of the new material, pointing out the important effect of hydroxyl concentration on the consolidation process [18].

Based on the work, in view of poor flame retardancy of the new material, a new type of self-made charring agent, Boz-F, was adopted to compound an intumescent flame retardant for the experimental study on the new material. Thermogravimetric experiments, thermal degradation kinetics, and the differential scanning calorimetry (DSC) analysis indicate that Boz-F has a high charring rate and proper decomposition activation energy, and thus it is a suitable charring agent of the intumescent flame retardant. Through a vertical firing test, a thermogravimetric analysis, Raman spectral and X-ray diffraction spectral analyses, it is proven that the composite achieves the best flame retardancy when the mass ratio of charring agent: red phosphorus: melamine is $2: 1: 2$. Besides, to avoid degradation of mechanical properties of the material induced by the application of intumescent flame retardant, hollow glass bubbles (HGB) were utilized for a mechanical modification experiment of the flame-retardant material. Related experiments show that the addition of HGB improves the compressive resistance and bending resistance of the new material [18].

After the above work, a green and safe sealing material with low viscosity and high permeability was developed for pressure measurement. Moreover, the interaction between the material and coal was experimentally studied to further investigate their interaction, the permeability of the material in coal, and the mechanical properties of coal-new material consolidated product (CNMCP). Besides, the sealing effect of the new material was also compared and investigated on site.

\section{Analysis of Stress Distribution of Coal around Bedding Drilling and the Failure Mechanism of Boreholes}

2.1. Stress Distribution Model and Zone Division of the Borehole along the Drilling Direction. When a drill bit is drilling a borehole along a coal seam, it will cause damage to the original coal. Due to the drilling operation, strain stress will redistribute in the whole coal. In the direction of drilling, some areas experience stress concentration; some areas undergo pressure relief; and others suffer little drilling-induced disturbance and basically maintain the original stress distribution. According to changes in stress, coal along the drilling direction can be divided into three zones [19], namely, the stress unloading zone (the pressure relief zone), the stress concentration zone (the concentration zone), and the original stress zone (the primary zone).

After a borehole is formed in coal, the stress redistributes. The maximum and minimum principal stresses around the borehole are the tangential and radial stresses, respectively. Based on the state of stress around a borehole, the area along the diameter direction can be divided into three zones, namely, plastic softening zone, plastic hardening zone, and elastic zone (the former two are collectively referred to plastic failure zone), as shown in Figure 1.

Like stress distribution in coal along the drilling direction, coal in the plastic failure zone features fracture development and low strength. Specifically, the plastic hardening zone and the elastic zone share similar fracture development and stress state, and the permeability and stress state of the two zones can even be regarded as the same. In the plastic softening zone, coal is loosened and damaged, with fracture development. The zone is in the stage of complete plastic deformation. It is a primary area that needs to be solidified and sealed in engineering practices such as gas pressure measurement. In the elastic zone, stress and pores are in their original state, or the coal is compacted due to stress concentration. The porosity and permeability are low in this zone. Thereby, the minimum permeation distance of the plugging material should be greater than the radius of the plastic softening zone, for ensuring the effectiveness of plugging. Besides, the larger the permeation radius is, the better the plugging effect becomes.

According to the relevant literature, the range of plastic softening zone of drilled coal and rock mass can be determined by equation (1) [20]:

$$
R_{\mathrm{s}}=R_{0}\left[\frac{2\left[\sigma_{0}\left(K_{p}-1\right)+(2 c \cos \varphi /(1-\sin \varphi))\right]}{\left(K_{p}+1\right)(2 c \cos \varphi /(1-\sin \varphi))}\right]^{1 /\left(K_{p}-1\right)}
$$

where $R_{\mathrm{s}}$ is the radius of the plastic softening zone, $R_{0}$ is the radius of the borehole, $\sigma_{0}$ is the original stress of the coal, $\phi$ is the internal friction angle of the coal, and $K_{p}=(1+\sin \varphi) /(1-\sin \varphi)$. 


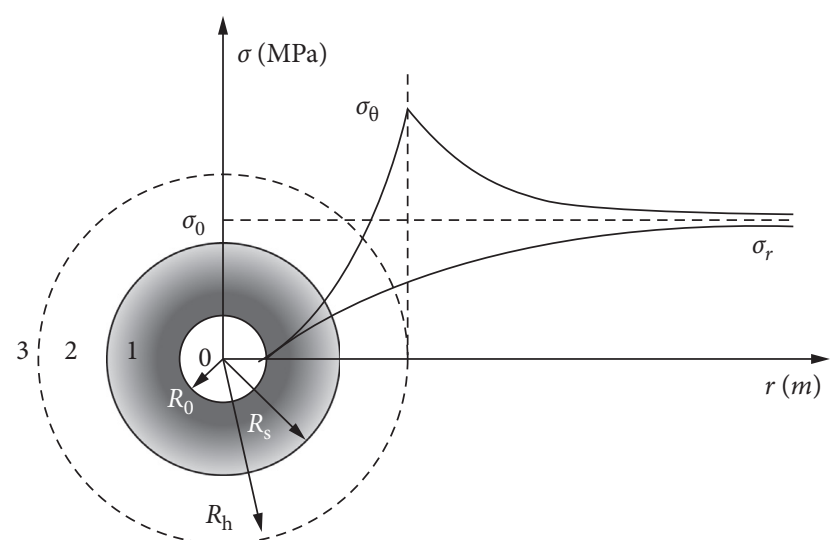

FIgURE 1: Stress distribution diagram of elastic-plastic zones of a borehole. $R_{0}$ is the radius of the borehole, $R_{\mathrm{s}}$ is the radius of the plastic softening zone, and $R_{\mathrm{h}}$ is the radius of the plastic hardening zone; 1 is the plastic softening zone, 2 is the plastic hardening zone, and 3 is the elastic zone.

2.2. Three Failure Modes of Bedding Drilling. The failure (instability) of bedding drilling is related to the structural failure of a bedding borehole itself and the stress state of surrounding coal. According to the failure (instability) areas, damage of a bedding borehole can be divided into two modes: (1) mechanical failure of the borehole structure and (2) the borehole structure instability and borehole collapse induced by the internal structural damage of coal around the borehole, which is frequently accompanied by jamming of drilling tools and spewing. The first mode can be subdivided into borehole-bottom failure (instability) and borehole-wall failure (instability), according to the failure location. Various modes, forms, and criteria for failure of bedding drilling are illustrated in Figure 2 [21-25].

After the new material is injected into a coal seam, it will exert an impact on the aforesaid three failure modes. For the sake of simplicity, studies are mainly conducted on the permeation and distribution of the material along the direction of borehole diameter. The new material, which permeates along the diameter direction, will change the mechanical properties of coal around the pore wall. Besides, it can interact with coal to form a coal-composite consolidated product with a certain strength, hence improving the mechanical properties of coal around the borehole wall and strengthening the coal seam.

The new material should permeate the plastic softening zone and bond well with coal to form a consolidated product, thereby reinforcing the plastic zone and achieving the purpose of sealing and strengthening. Hence, the permeability and consolidation effect of the plugging material need to be investigated.

\section{Experimental Study on Permeability of the New Material in Coal}

3.1. Experimental Study. The experiment was carried out via a simulation experimental device of coal seam outburst developed by China University of Mining and Technology. The device mainly consists of a press, an obround cylinder, a compression column, and a plug. It has the maximum test load of $10,000 \mathrm{kN}$. The obround has two semicircular ends with a radius of $110 \mathrm{~mm}$ and two parallel lines with a length of $900 \mathrm{~mm}$. The depth of the cylinder is $330 \mathrm{~mm}$. With the maximum test load, the formation pressure of a coal seam can reach $42.37 \mathrm{MPa}$, and the outburst coal such as Grade IV coal and Grade V coal can be prepared on site [26]. In the permeability experiment, coal samples from Wangzhuang Coal Mine were first crushed in the laboratory and then sieved to obtain coal particles with a size of below $1 \mathrm{~mm}$. Next, an appropriate volume of water was added to the particles and the mixture was stirred evenly before they were sealed in a tank. To fully compact coal samples, the coal seam pressing was carried out five times. The thickness of a coal seam was about $45 \mathrm{~mm}$ each time. The coal seam was kept for $30 \mathrm{~min}$ under the formation pressure of $35 \mathrm{MPa}$ to discharge gas from it, which was beneficial to the combination between samples.

After the layered pressing, the confining pressure was maintained at $10 \mathrm{MPa}$ by the press for $12 \mathrm{~h}$, in order to make properties of the briquette uniform and stable. Then, a pipe with a diameter of $42 \mathrm{~mm}$ driven by a coal electric drill drilled into the simulated coal seam from the plug side. After the formation of a borehole, sealing materials with the same mass $(1 \mathrm{~kg})$ were injected in them for a material permeability test. After the materials were solidified and molded for $12 \mathrm{~h}$, superfluous coal was removed to obtain coal-material consolidated product. Next, 5 sections were cut from the consolidated material at an equal distance, and the maximum radial dimensions of sections were measured. According to the corresponding physical meaning, the difference between the maximum radial dimension and the borehole diameter $(42 \mathrm{~mm})$ is defined as the effective consolidation distance of the material into a coal seam, for investigating the permeability of the material. Specific steps are illustrated in Figure 3. Comparison of effective consolidation distances of two different materials after they permeate the coal seam is given in Table 1 .

It can be observed from Table 1 that the effective consolidation distances of the new material are all larger than those of polyurethane. The maximum, minimum, and average values of the effective consolidation distance of the new material in the coal matrix are $33 \mathrm{~mm}, 27 \mathrm{~mm}$, and $29.4 \mathrm{~mm}$, respectively, while those of polyurethane are $22 \mathrm{~mm}, 20 \mathrm{~mm}$, and $21 \mathrm{~mm}$, respectively. The average value of the new material is $40.0 \%$ higher than that of polyurethane.

3.2. Investigation on Permeation Effect. In order to further quantify the permeability of the new material, relevant parameters of coal samples collected from Wangzhuang Coal Mine were combined with equation (1) to calculate the radius $R_{\mathrm{s}}$ of the plastic softening zone. In addition, half of the average of the maximum radial dimension of consolidated products was defined as the permeation radius of the material. The comparison between the permeation radii of materials and the radius of plastic softening zone is shown in Table 2. 


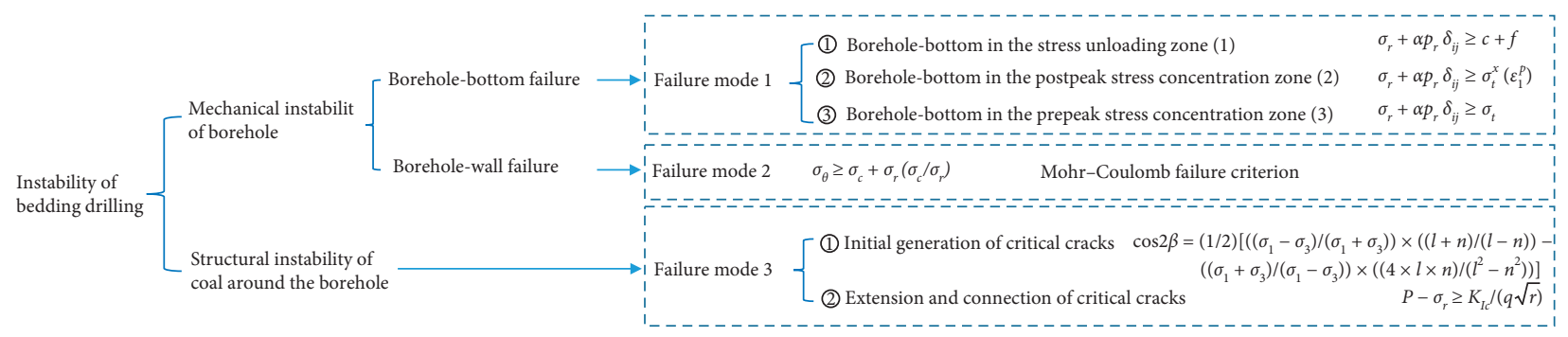

FIGURE 2: Three failure modes of bedding drilling.

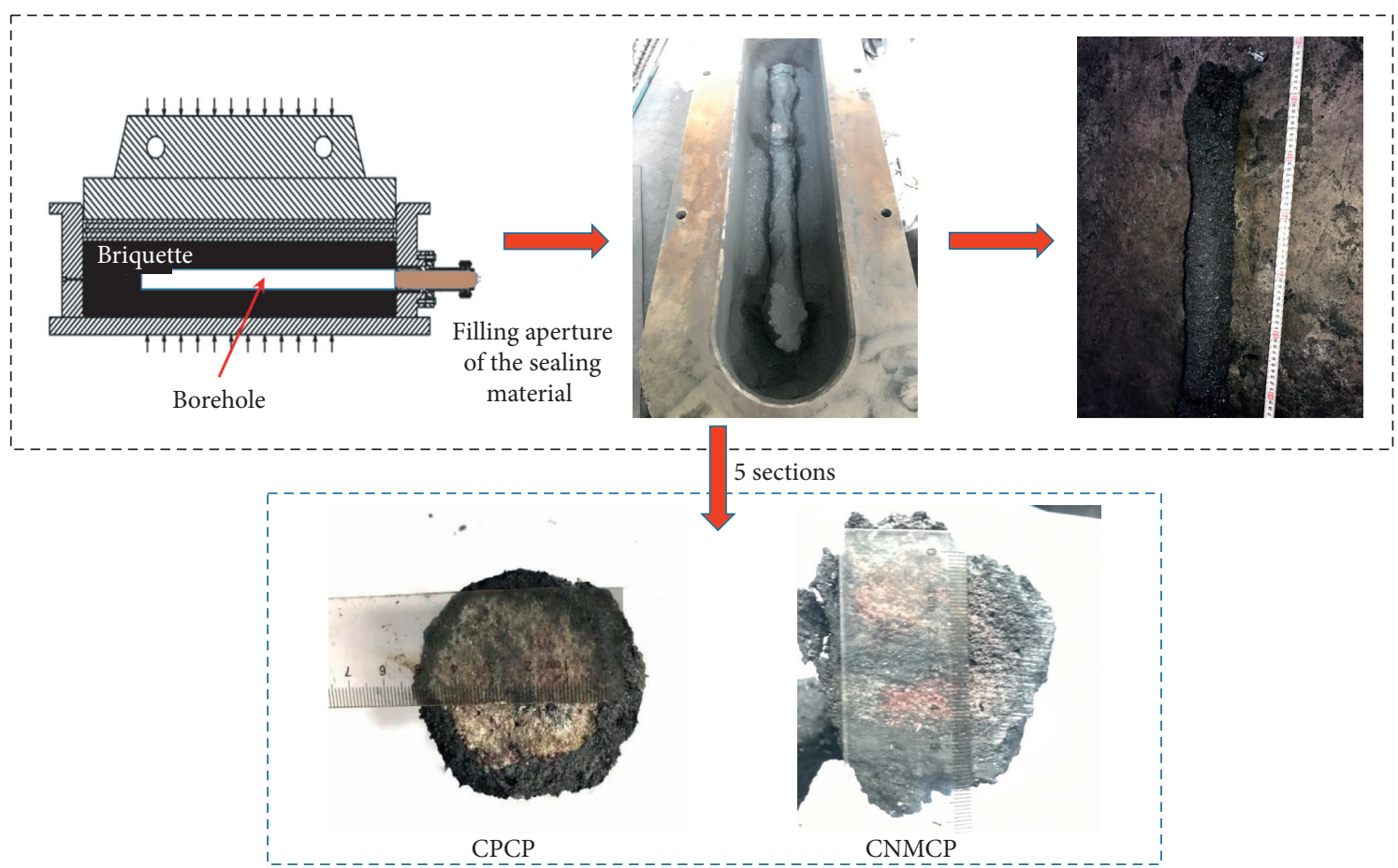

FIGURE 3: Schematic diagram of the experimental process of material permeability in coal.

TABLE 1: Comparison of effective consolidation distances of materials in coal.

\begin{tabular}{|c|c|c|c|c|c|c|c|}
\hline Indexes & Material type & $\begin{array}{c}\text { Section } 1 \\
(\mathrm{~mm})\end{array}$ & $\begin{array}{l}\text { Section } 2 \\
(\mathrm{~mm})\end{array}$ & $\begin{array}{c}\text { Section } 3 \\
(\mathrm{~mm})\end{array}$ & Section 4 & $\begin{array}{c}\text { Section } 5 \\
(\mathrm{~mm})\end{array}$ & $\begin{array}{l}\text { Average } \\
(\mathrm{mm})\end{array}$ \\
\hline \multirow{2}{*}{$\begin{array}{l}\text { Effective consolidation } \\
\text { distance }\end{array}$} & Polyurethane & 22 & 21 & 22 & 20 & 20 & 21 \\
\hline & New material & 29 & 27 & 30 & 28 & 33 & 29.4 \\
\hline
\end{tabular}

TABLE 2: Comparison between the experimentally obtained permeation radii of materials and the calculated radius of plastic softening zone ( $A$ refers to polyurethane and $B$ represents the new material).

\begin{tabular}{lcccccc}
\hline $\begin{array}{l}\text { Coal sample } \\
\text { source }\end{array}$ & $\begin{array}{c}\text { Borehole } \\
\text { radius }(\mathrm{mm})\end{array}$ & $\begin{array}{c}\text { Original } \\
\text { stress }(\mathrm{MPa})\end{array}$ & $\begin{array}{c}\text { Internal } \\
\text { friction angle } \\
\left({ }^{\circ}\right)\end{array}$ & $\begin{array}{c}\text { Cohesion } \\
(\mathrm{MPa})\end{array}$ & $\begin{array}{c}\text { Calculated value } \\
\text { of } R_{\mathrm{s}}(\mathrm{mm})\end{array}$ & $\begin{array}{c}\text { Permeation radius } \\
\text { of } A(\mathrm{~mm})\end{array}$ \\
\hline $\begin{array}{l}\text { Wangzhuang } \\
\text { coal mine }\end{array}$ & 21 & 10 & 28 & 1.4 & 35.6 & 31.5 \\
\hline
\end{tabular}

Table 2 reflects that the experimentally obtained permeation radius of the new material is larger than the radius of the plastic softening zone. In other words, the new material can not only completely permeate the plastic softening zone to play a better role in sealing and bonding, but also effectively strengthen the broken coal. Besides, it has obvious better permeation effect in coal than polyurethane, a kind of traditional sealing material. Furthermore, it can consolidate loose coal in plastic softening zone, boasting good application effect on sealing fracture and 
solidifying coal seams. Due to the limited experimental conditions, the injection was only performed under atmospheric pressure, while the pressed injection test was not carried out. If the injection had been performed under a low pressure, the permeation effect of the material could have been better.

\section{Study on Mechanical Properties of Coal-Composite Consolidated Products}

During gas pressure measurement through bedding drilling, a consolidated product will be formed by the injected material and the coal particles. Mechanical properties of the consolidated product, which directly affect the reinforcement and sealing effect of boreholes, are mainly reflected by the compressive strength and bending strength of sample. When the consolidated product is subjected to compressive and bending stresses, the greater the compressive and bending strengths are, the stronger the antideformation ability of borehole is, and thus the more integrated the borehole wall will be. Therefore, the study on mechanical properties of coal-composite consolidated products, especially the comparison of compressive and bending strengths between the coal-polyurethane consolidated product CPCP and the CNMCP, can facilitate the understanding of how to improve the performance of new material. In this section, a test was conducted on mechanical properties of the CPCP and the CNMCP. Experimental samples were prepared according to the formulation in Tables 3 and 4, respectively, to obtain two types of consolidated products. Then, test samples were cut by a press cutter, as displayed in Figure 4 .

4.1. Experimental Material. Isocyanate is produced by Wanhua Chemical Group Co., Ltd., Yantai, Shandong Province. Polylactide polyol (including foaming agent) is made by Shenzhen Esun Industrial Co., Ltd. Boz-F, a new kind of charring agent, is self-made. Red phosphorus is manufactured by Guangdong Fantian Technology Co., Ltd. Melamine is provided by Sinopharm Chemical Reagent Co., Ltd. VS5500 HGB comes from the 3M Company (China). Pulverized coal is the broken coal with a diameter of $1 \mathrm{~mm}$ or less after screening, from Xinyuan Coal Mine, Shanxi province.

4.2. Experimental Material Preparation. The prepared samples of coal-composite consolidated products for the mechanical property test are shown in Figure 4.

\subsection{Mechanical Property Test}

4.3.1. Compression Test. Figure 5 demonstrates compressive stress-strain curves for six different formulations of CPCP at a loading speed of $1 \mathrm{~mm} / \mathrm{min}$.

It can be seen from curves in Figure 5 that when the consolidated product with the addition of pulverized coal is subjected to compressive stress, it shows complex compression fracture behaviors as the addition amount changes. In $\mathrm{J}-4$, the curve exhibits certain characteristics of ductile fracture. The CPCP yields without obvious fractures when the compressive stress reaches 4.5 MPa. Instead, its compressive stress decreases slightly with the increase of compressive strain. As compressive deformation reaches 0.38 , compressive stress continues to grow to the maximum value of $4.64 \mathrm{MPa}$. At this point, the CPCP breaks. The CPCPs with the rest formulations have typical brittle fracture behaviors, that is, when the compressive stress they bear reaches the maximum, they will find the formation of obvious cracks and will be destroyed. As a kind of filler like inorganic particles, pulverized coal can mix with polyurethane to form a consolidated product. When the consolidated product is subjected to compressive stress, abundant crazes are induced in a direction perpendicular to the compressive stress. These crazes are a kind of viscoelastic medium with a certain mechanical strength, so they can induce the ductile fracture of the consolidated product. However, under the action of continuous external force, crazes will break and turns into cracks, which destroys the consolidated product. A small amount of pulverized coal can be uniformly mixed with polyurethane to produce few crazes, causing fracture damage to the composite when the overall material reaches the limit of compressive yield (J-5 and J-6). With a high content of pulverized coal (J-1, J-2, and $\mathrm{J}-3)$, mechanical properties of the overall composite degrade because of the incompatibility between pulverized coal and polyurethane and the poor strength of pulverized coal itself. Only with an appropriate volume of pulverized coal can crazes be generated (J-4), which enhances the compressive strength of the coal-polyurethane composite.

Figure 6 presents compressive stress-strain curves for six different formulations of CNMCP at a loading speed of $1 \mathrm{~mm} / \mathrm{min}$.

Different from CPCPs, all the CNMCPs are characterized by brittle fracture. In addition, except for some individual points, compressive strength of CNMCP rises from 4.36 MPa to $7.14 \mathrm{MPa}$, with the declining addition of pulverized coal and the growing content of the new material. When more pulverized coal and less new material are added, the consolidated product has low compressive resistance because it cannot be effectively reinforced by the insufficiently added new material and the low-strength pulverized coal. Instead, when less pulverized coal and more new material are added, HGB in the new material can effectively enhance the rigidity. As a result, the consolidated product possesses high compressive resistance and improved compressive strength.

Table 5 gives a comparison between compressive strengths of CPCP and CNMCP. On the premise of the same mass ratio, the CNMCP has a greater compressive strength than the CPCP. To quantitatively compare compressive strengths of the two, (the compressive strength of CPCP-the compressive strength of $\mathrm{CNMCP}$ )/the compressive strength of CPCP is defined as the percentage of enhancement. The result shows that compressive strength of CNMCP is 153\% higher than that of CPCP. In other words, the new material interacts more strongly with coal and boasts better performance of permeating coal and bonding loose coal seam than traditional polyurethane. 
TABLE 3: Composition of CPCP.

\begin{tabular}{lcccc}
\hline No. & Polyether polyol $4110(\mathrm{~g})$ & Isocyanate $(\mathrm{g})$ & Catalyst $(\mathrm{g})$ & Pulverized coal $(\mathrm{g})$ \\
\hline J-1 & 40 & 40 & 0.4 & 100 \\
J-2 & 40 & 40 & 0.4 & 90 \\
J-3 & 40 & 40 & 0.4 & 80 \\
J-4 & 40 & 40 & 0.4 & 70 \\
J-5 & 40 & 40 & 0.4 & 60 \\
J-6 & 40 & 40 & 0.4 & 50 \\
\hline
\end{tabular}

TABLE 4: Composition of CNMCP.

\begin{tabular}{|c|c|c|c|c|c|c|c|c|c|}
\hline No. & $\begin{array}{l}\text { Polylactide } \\
\text { polyol (g) }\end{array}$ & $\begin{array}{c}\text { Polyether polyol } \\
4110(\mathrm{~g})\end{array}$ & $\begin{array}{c}\text { Isocyanate } \\
\text { (g) }\end{array}$ & $\begin{array}{l}\text { Charring } \\
\text { agent }(\mathrm{g})\end{array}$ & $\begin{array}{c}\text { Red phosphorus } \\
\text { (g) }\end{array}$ & $\begin{array}{c}\text { Melamine } \\
(\mathrm{g})\end{array}$ & $\begin{array}{l}\text { Catalyst } \\
(\mathrm{g})\end{array}$ & $\begin{array}{l}\text { HGB } \\
(\mathrm{g})\end{array}$ & $\begin{array}{c}\text { Pulverized } \\
\text { coal }(\mathrm{g})\end{array}$ \\
\hline $\mathrm{X}-1$ & 16 & 24 & 40 & 8 & 4 & 8 & 0.4 & 12 & 100 \\
\hline $\mathrm{X}-2$ & 16 & 24 & 40 & 8 & 4 & 8 & 0.4 & 12 & 90 \\
\hline $\mathrm{X}-3$ & 16 & 24 & 40 & 8 & 4 & 8 & 0.4 & 12 & 80 \\
\hline $\mathrm{X}-4$ & 16 & 24 & 40 & 8 & 4 & 8 & 0.4 & 12 & 70 \\
\hline $\mathrm{X}-5$ & 16 & 24 & 40 & 8 & 4 & 8 & 0.4 & 12 & 60 \\
\hline $\mathrm{X}-6$ & 16 & 24 & 40 & 8 & 4 & 8 & 0.4 & 12 & 50 \\
\hline
\end{tabular}

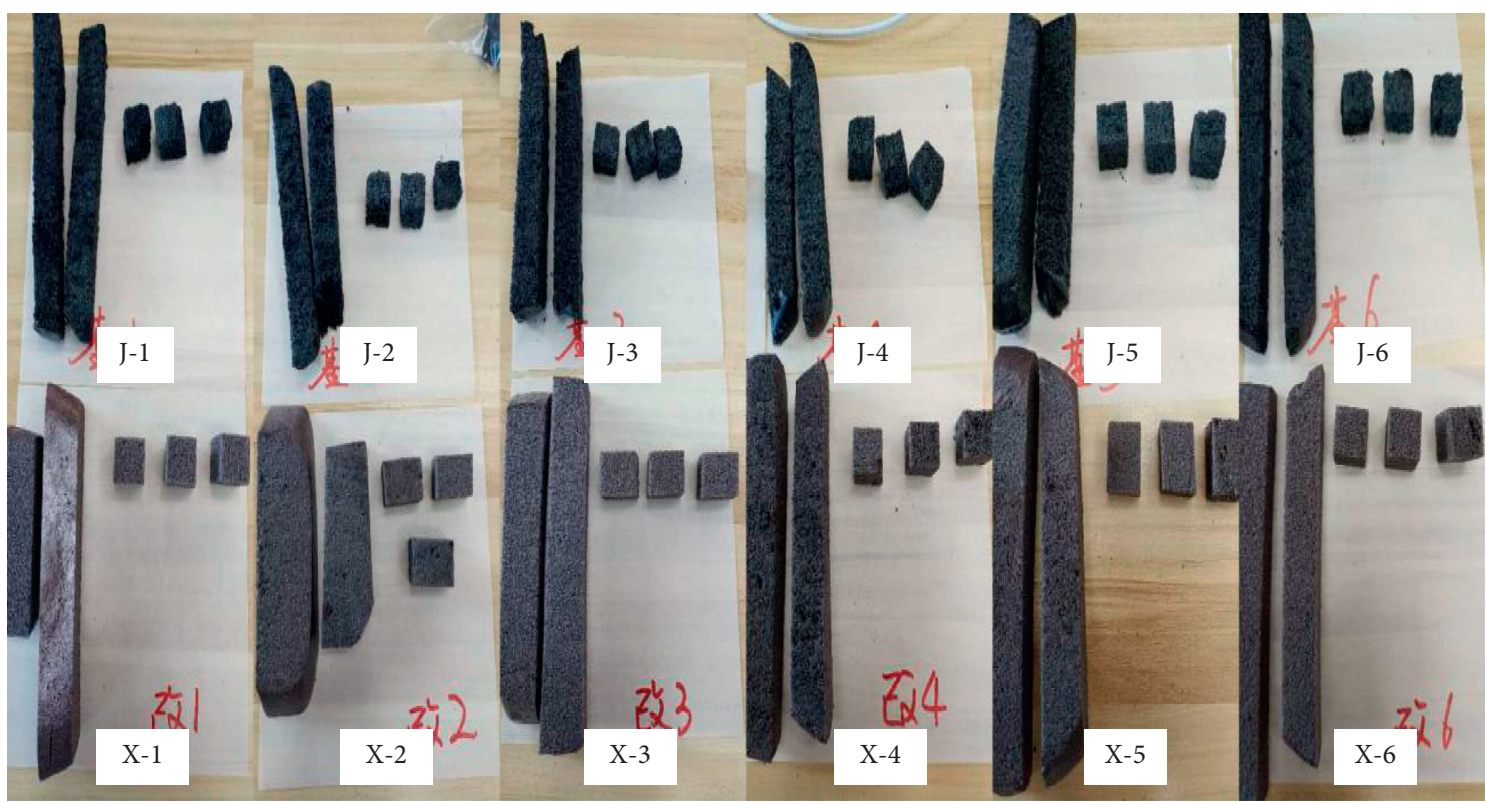

FIGURE 4: Samples of coal-composite consolidated products for the mechanical property test.

4.3.2. Bending Test. Bending stress-strain curves for six different formulations of CPCP at a loading speed of $1 \mathrm{~mm} /$ min are displayed in Figure 7.

After the addition of pulverized coal, all the CPCPs show obvious brittle fracture behaviors. An optimal ratio of pulverized coal to polyurethane exists for the improvement of bending performance. It is obvious that when a large amount of pulverized coal is added, both the bonding effect of polyurethane on pulverized coal and the strength of CPCP are weakened. This is because pulverized coal, which is not a kind of polymer material, shares no compatibility with polyurethane. The continuity of the organic system of polyurethane is destroyed with the addition of a great amount of pulverized coal. Besides, pulverized coal itself has low strength, thus lowering the bending performance of the whole composite. When a small amount of pulverized coal is added, the prepared polyurethane, a kind of rigid foam material, will see the acceleration of destruction due to the breakage of cells under a bending force. When an intermediate optimal amount of pulverized coal is added, the added coal will effectively fill cells of rigid polyurethane foams, without causing damage to the continuous structure of cell walls of polyurethane. During the bending failure process, the coal will effectively absorb the shock of external load. As a result, the bending strength of composite reaches the maximum value.

Figure 8 illustrates bending stress-strain curves for six different formulations of CNMCP at a loading speed of $1 \mathrm{~mm} / \mathrm{min}$.

As can be seen from Figure 8, the addition of pulverized coal has a great influence on the brittle-ductile fracture behaviors of CNMCPs. As the addition of pulverized coal 


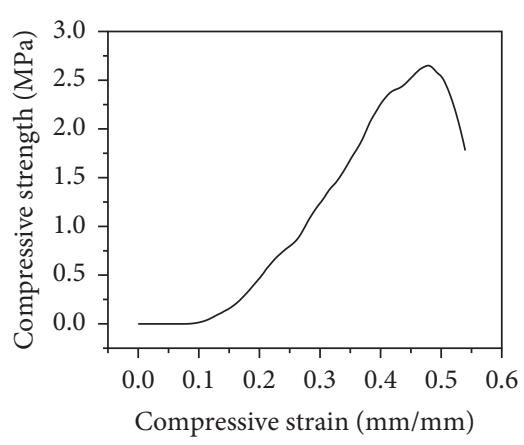

(a)

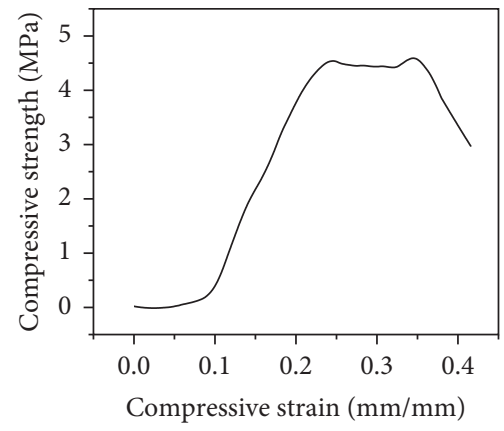

(d)

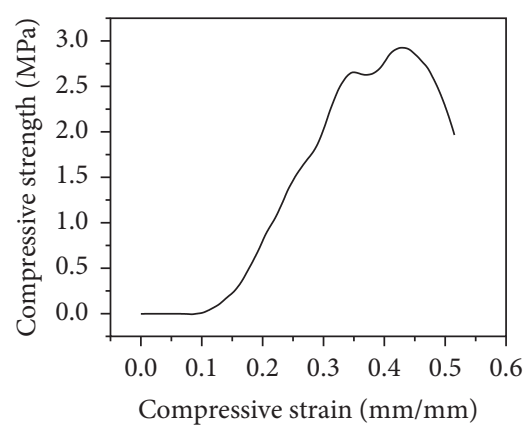

(b)

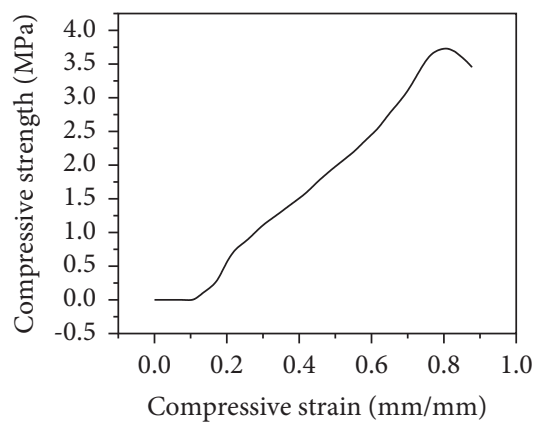

(e)

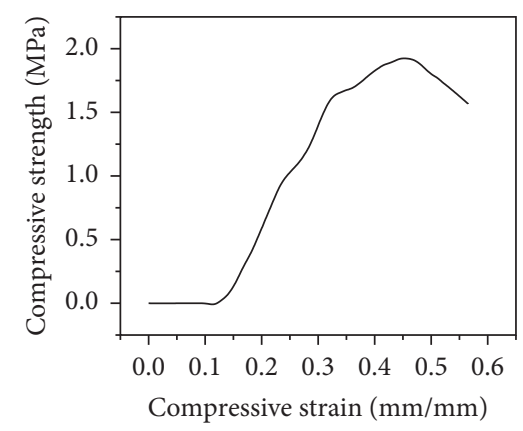

(c)

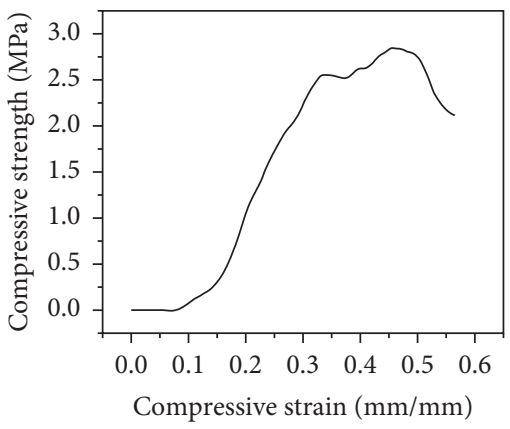

(f)

FIgURE 5: Compressive stress-strain curves of CPCP. (a). J-1. (b). J-2. (c). J-3. (d). J-4. (e). J-5. (f). J-6.

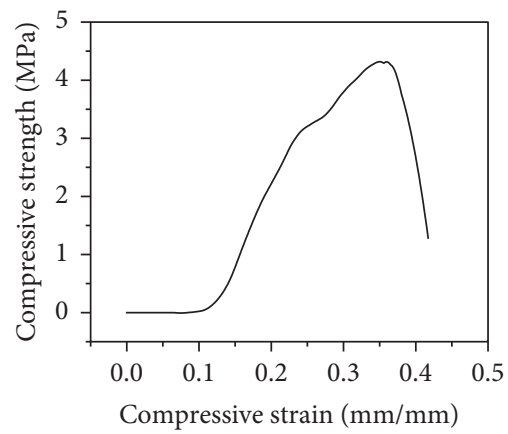

(a)

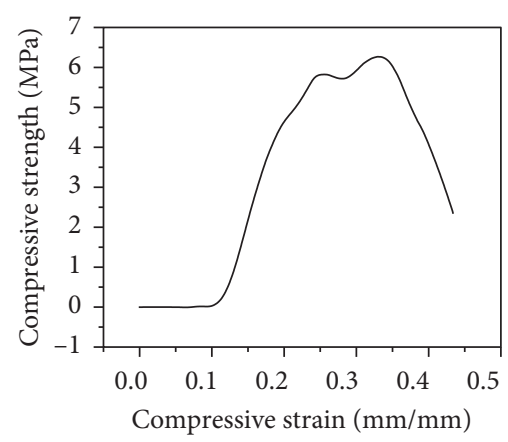

(d)

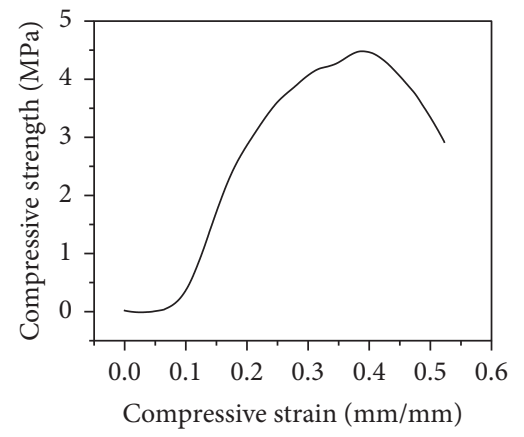

(b)

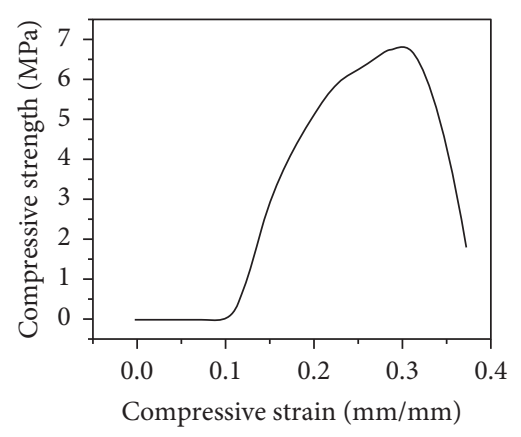

(e)

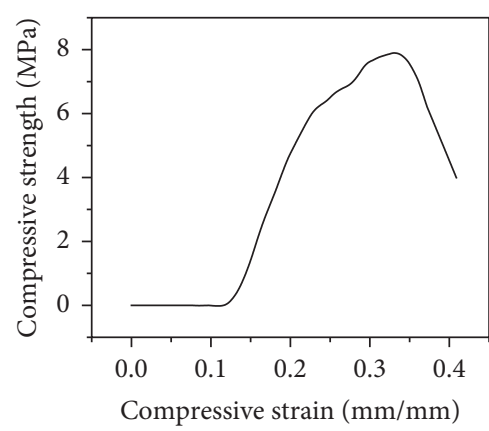

(c)

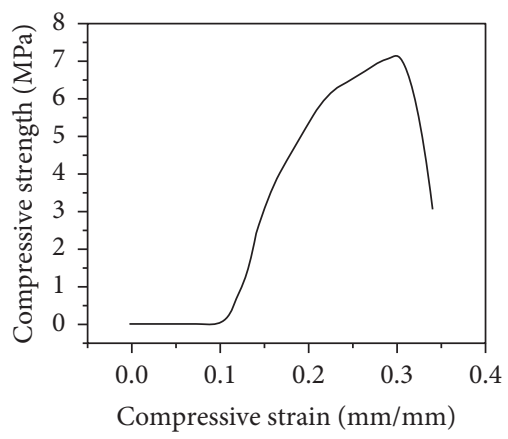

(f)

Figure 6: Compressive stress-strain curves of CNMCP. (a). X-1 (b). X-2 (c). X-3 (d). X-4 (e). X-5 (f). X-6.

increases, the fracture behavior of CNMCP gradually changes from hard and brittle (X-6 and X-5) to soft and weak $(\mathrm{X}-1)$. Table 6 shows the comparison between the bending strengths of CPCP and CNMCP.
Except for some individual points, the compressive strength of CNMCP grows as the addition of pulverized coal decreases. With low content of pulverized coal, HGB in the composite can enhance the rigidity. Besides, the small 
TABLE 5: Comparison between compressive strengths of CPCP and CNMCP.

\begin{tabular}{|c|c|c|c|c|c|c|c|}
\hline \multicolumn{2}{|c|}{ Mass of the added pulverized coal (g) } & 100 & 90 & 80 & 70 & 60 & 50 \\
\hline \multirow{2}{*}{ Compressive strength $(\mathrm{MPa})$} & Coal-polyurethane & 2.65 & 3.01 & 1.94 & 4.64 & 3.73 & 2.92 \\
\hline & Coal-new material & 4.36 & 4.50 & 4.90 & 6.38 & 6.81 & 7.14 \\
\hline Percent of enhancement (\%) & & 64.5 & 49.5 & 153 & 37.5 & 82.5 & 145 \\
\hline
\end{tabular}

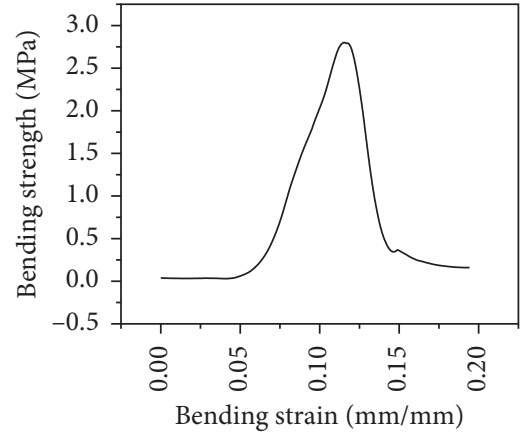

(a)

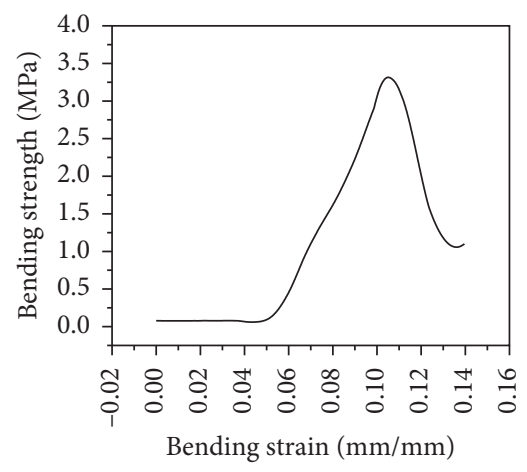

(d)

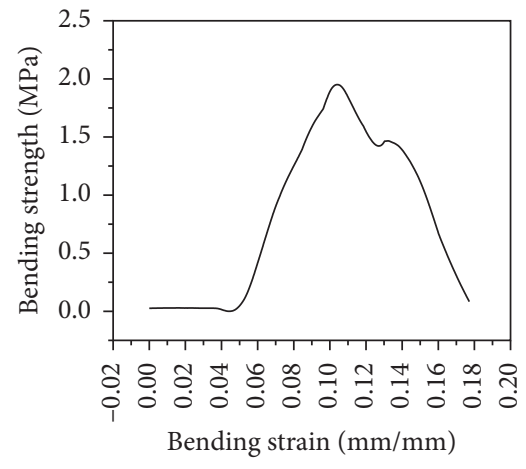

(b)

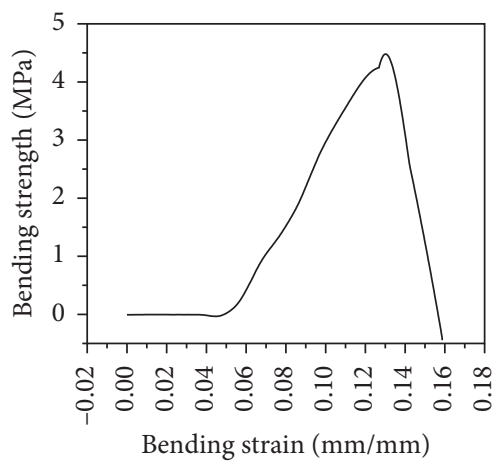

(e)

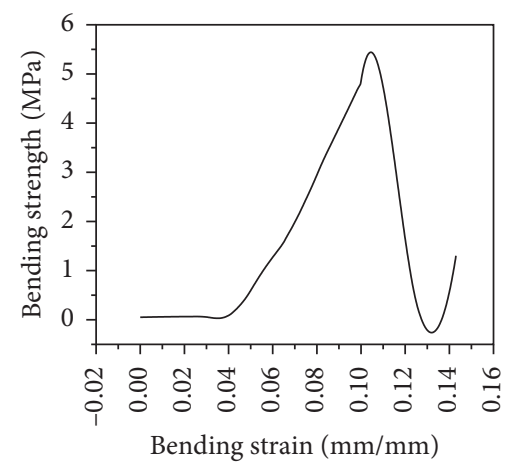

(c)

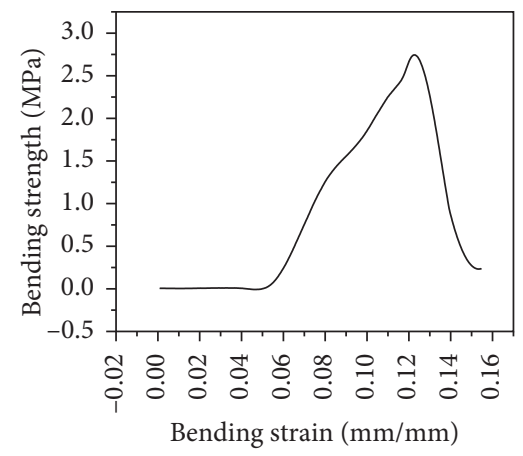

(f)

Figure 7: Bending stress-strain curves of CPCP. (a). J-1. (b). J-2. (c). J-3. (d). J-4. (e). J-5. (f). J-6.

amount of pulverized coal can uniformly disperse in the cells formed during the foaming process of the material, which makes foaming of the new material more difficult. Accordingly, the density of CNMCP is further improved, and its mechanical strength is enhanced.

On the premise of the same mass ratio, the bending strength of CNMCP is larger than that of CPCP (excluding $\mathrm{X}-3$ ) and is up to $161 \%$ greater than the compressive strength of CPCP. The new material exhibits stronger interaction with coal and better performance of permeating coal and bonding loose coal seam than traditional polyurethane.

\section{Industrial Test}

The test was conducted in Xinyuan Coal Mine, Shanxi Province, China. The actual application effect of pressure measurement with the new material was verified by measuring the original gas pressure in No. 3 coal seam of the mine. No. 3 coal seam is about $23 \mathrm{~m}$ away from the upper $\mathrm{K}_{8}$ sandstone and is in the middle of Shanxi Group. According to the drilling data of exploration and construction, most of the coal seam is recoverable, except No. 1, No. 2, and No. P30 boreholes near the western boundary and No. P75 borehole near the northeast boundary of the minefield. The thickness of the coal seam lies in the range of $0.40-4.75 \mathrm{~m}$ and averages $2.58 \mathrm{~m}$. The coal seam is mostly recoverable and stable with a recoverable area of $128.787 \mathrm{~km}^{2}$, a thickness variation coefficient of $24 \%$, and a recoverability index of 0.97 . Besides, it contains 0-3 layers of stone and partially 6 layers. It has a simple structure. The coal seam roof generally consists of mudstone, sandy mudstone, siltstone, fine/medium/coarse sandstone, and partially carbon mudstone, while its floor is mainly composed of mudstone, sandy mudstone, fine sandstone, siltstone, carbon mudstone, and partially coarse sandstone. The coal seam has now formed a certain area of goaf in the north central part of the minefield.

Four groups of boreholes were drilled in No. 3 coal seam. Each group included two pressure-measuring boreholes arranged in the coal seam. After the drilling was completed, polyurethane and the new material were applied to pregrouting. The former was used for No. 2, No. 4, No. 6, and No. 8 boreholes, while the latter was adopted for No. 1, No. 3, No. 5, and No. 7 boreholes. Specific technical parameters and measurement results are listed in Table 7. 


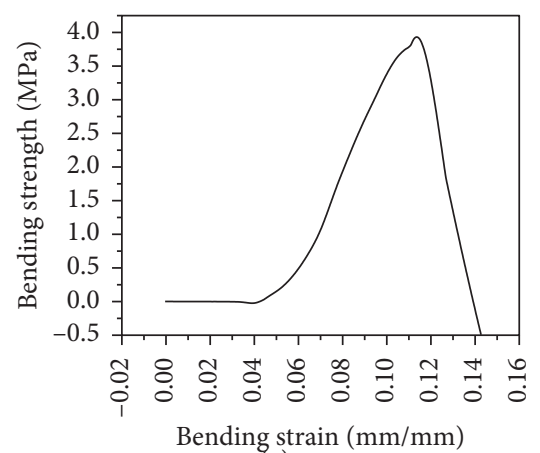

(a)

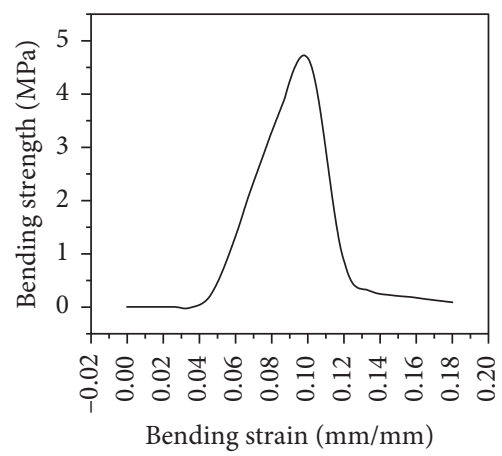

(d)

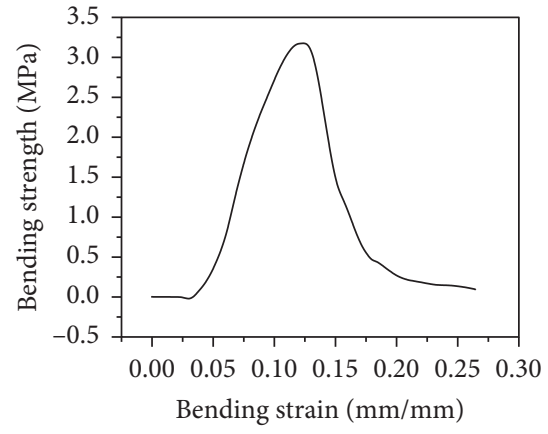

(b)

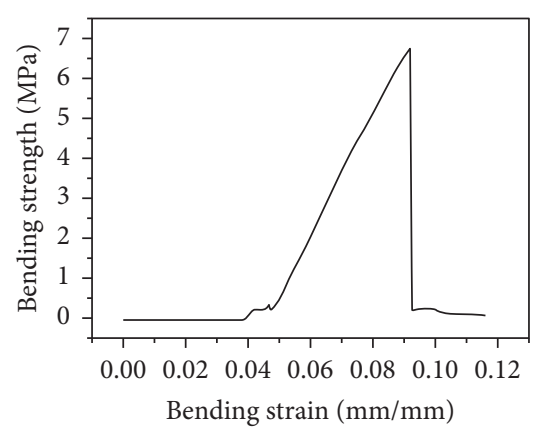

(e)

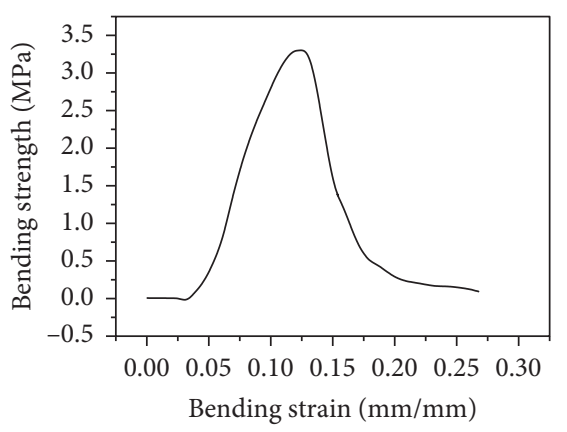

(c)

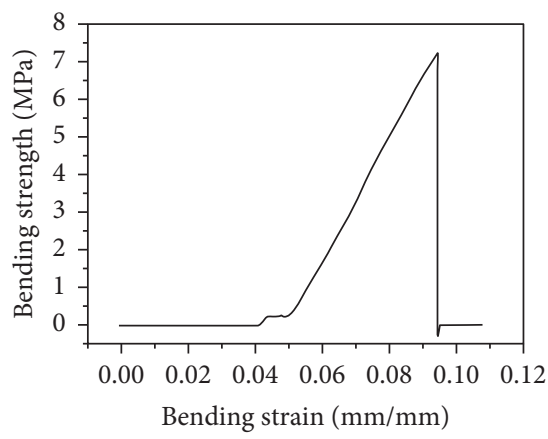

(f)

Figure 8: Bending stress-strain curves of CNMCP. (a). X-1 (b). X-2 (c). X-3 (d). X-4 (e). X-5 (f). X-6.

TABLE 6: Comparison between bending strengths of CPCP and CNMCP.

\begin{tabular}{llcccccc}
\hline \multicolumn{2}{c}{ Mass of the added pulverized coal (g) } & 100 & 90 & 80 & 70 & 60 & 50 \\
\hline \multirow{2}{*}{ Bending strength $(\mathrm{MPa})$} & Coal-polyurethane & 2.94 & 2.13 & 5.32 & 3.50 & 4.34 & 2.77 \\
Percent of enhancement (\%) & Coal-new material & 3.86 & 3.17 & 3.31 & 5.00 & 6.76 & 7.25 \\
\hline
\end{tabular}

TABLE 7: Technical parameters of pressure-measuring boreholes.

\begin{tabular}{|c|c|c|c|c|c|c|c|}
\hline & No. & Location & $\begin{array}{l}\text { Elevation } \\
(\mathrm{m})\end{array}$ & $\begin{array}{l}\text { Buried depth } \\
(\mathrm{m})\end{array}$ & $\begin{array}{c}\text { Dip } \\
\left({ }^{\circ}\right)\end{array}$ & $\begin{array}{l}\text { Actual hole length } \\
(\mathrm{m})\end{array}$ & $\begin{array}{c}\text { Measured pressure } \\
(\mathrm{MPa}) \\
\end{array}$ \\
\hline \multirow{2}{*}{$\begin{array}{l}\text { Comparative } \\
\text { group } 1\end{array}$} & $1 \#$ & $\begin{array}{l}1,471 \mathrm{~m} \text { from no. } 3108 \text { return } \\
\text { roadway }\end{array}$ & 636 & 463 & 2 & 55.2 & 0.39 \\
\hline & 2\# & $\begin{array}{l}1,491 \mathrm{~m} \text { from no. } 3108 \text { return } \\
\text { roadway }\end{array}$ & 636 & 463 & 2 & 55.7 & 0.38 \\
\hline \multirow{2}{*}{$\begin{array}{l}\text { Comparative } \\
\text { group } 2\end{array}$} & 3\# & $\begin{array}{c}1,223 \mathrm{~m} \text { from no. } 3108 \text { return } \\
\text { roadway }\end{array}$ & 627 & 472 & 2 & 53.7 & 0.41 \\
\hline & $4 \#$ & $\begin{array}{c}1,203 \mathrm{~m} \text { from no. } 3108 \\
\text { working face }\end{array}$ & 628 & 471 & 2 & 53.6 & 0.41 \\
\hline \multirow{2}{*}{$\begin{array}{l}\text { Comparative } \\
\text { group } 3\end{array}$} & 5\# & $\begin{array}{c}1,100 \mathrm{~m} \text { from no. } 3412 \text { return } \\
\text { roadway }\end{array}$ & 594 & 505 & 2 & 55.8 & 0.52 \\
\hline & $6 \#$ & $\begin{array}{l}1,125 \mathrm{~m} \text { from no. } 3412 \text { return } \\
\text { roadway }\end{array}$ & 596 & 503 & 2 & 55.4 & 0.50 \\
\hline \multirow{2}{*}{$\begin{array}{l}\text { Comparative } \\
\text { group } 4\end{array}$} & 7\# & $\begin{array}{l}290 \mathrm{~m} \text { from no. } 3412 \text { return } \\
\text { roadway }\end{array}$ & 579 & 520 & 2 & 53.2 & 0.67 \\
\hline & 8\# & $\begin{array}{l}310 \mathrm{~m} \text { from no. } 3412 \text { return } \\
\text { roadway }\end{array}$ & 576 & 523 & 1 & 53.3 & - \\
\hline
\end{tabular}

The construction of pressure-measuring boreholes by bedding drilling and the analyses on measurement results of gas pressure in Table 7 demonstrate that during the secondary borehole formation by bedding drilling, the new material can permeate the loose layer deep and interact with coal due to its excellent low-pressure permeability. The 
pregrouting by the new material for reinforcement and sealing can better strengthen the coal and seal cracks, and the pressure-measuring boreholes are hard to collapse after formation. In the field practice of pressure measurement, boreholes with the new material can be constructed normally, and the sealing capsule can be smoothly put into the predetermined position, ensuring the success of pressure measurement via bedding drilling. However, of the four boreholes plugged and reinforced by polyurethane, one (No. 8 ) collapses in the secondary borehole formation process. The capsule fails to be put in the right position, which results in failure of pressure measurement.

\section{Conclusions}

(1) Based on analyses of stress distribution of coal around bedding drilling, there are three failure modes of bedding drilling, namely, partial boreholebottom failure, partial borehole-wall failure, and structural instability of coal surrounding the borehole.

(2) The interaction between the new material and coal was studied to investigate the permeability of the new material in coal. The experimental results prove that the new material possesses better properties than the traditional polyurethane. The maximum and minimum effective consolidation distances $(33 \mathrm{~mm}$ and $27 \mathrm{~mm}$, respectively) of the new material in coal are higher than those (22 $\mathrm{mm}$ and $20 \mathrm{~mm}$, respectively) of polyurethane. Besides, the average effective consolidation distance increases from $21 \mathrm{~mm}$ to $29.4 \mathrm{~mm}$, with an increase of $40 \%$. Furthermore, under the original coal stress of $10 \mathrm{MPa}$, the relationship between the experimental value of permeation radius of the new material and the theoretical value of radius of the plastic softening zone is also explored. The results reveal that the new material can better permeate the plastic softening zone than polyurethane and can thus more effectively consolidate the broken coal.

(3) To research the bonding effect between the new material and coal, a test was performed on mechanical properties of CNMCP. The results indicate that the CNMCP has better mechanical properties than CPCP. With the same mass ratio, the enhancement of compressive and bending strength of CNMCP is up to $153 \%$ and $161 \%$, respectively, and the lowest enhancement can also reach $37.5 \%$ and $31.3 \%$, respectively.

\section{Data Availability}

The original data used to support the findings of this study are available from the corresponding author upon request.

\section{Conflicts of Interest}

The authors declare that there are no conflicts of interest regarding the publication of this paper.

\section{Acknowledgments}

Special thanks should be given to equal first author $\mathrm{Ao} \mathrm{Li}$, who has contributed equally to author Yujia Chen. This study was completed through the considerable effective work on data processing and analysis by both the authors. This work was supported by the National Natural Science Foundation of China (41802188), the Natural Science Foundation of Jiangsu Province (BK20150180) and the Priority Academic Program Development of Jiangsu Higher Education Institutions (PAPD).

\section{References}

[1] V. Václavík, J. Daxner, J. Valíček et al., "Utilization of sludge from mine water treatment plant in the segment of thermal insulation mortars," Archives of Environmental Protection, vol. 40, no. 1, pp. 51-59, 2014.

[2] A. Tosun, "Development of a technology to prevent spontaneous combustion of coal in underground coal mining," Journal of the Southern African Institute of Mining and Metallurgy, vol. 117, no. 12, pp. 1133-1138, 2017.

[3] A. Verma, G. Chauhan, and K. Ojha, "Synergistic effects of polymer and bentonite clay on rheology and thermal stability of foam fluid developed for hydraulic fracturing," Asia-Pacific Journal of Chemical Engineering, vol. 12, no. 6, pp. 872-883, 2017.

[4] Z. Ge, X. Mei, Y. Lu, J. Tang, and B. Xia, "Optimization and application of sealing material and sealing length for hydraulic fracturing borehole in underground coal mines," Arabian Journal of Geosciences, vol. 8, no. 6, pp. 3477-3490, 2015.

[5] F.-b. Zhou, B.-b. Shi, Y.-k. Liu, X.-l. Song, J.-w. Cheng, and S.-y. Hu, "Coating material of air sealing in coal mine: clay composite slurry (CCS)," Applied Clay Science, vol. 80-81, no. 4, pp. 299-304, 2013.

[6] X.-m. Guan, Z.-p. Yang, and C.-j. Zhang, "Bonding mechanism between waterglass/polyurethane adhesive and coal," The Journal of Adhesion, vol. 88, no. 9, pp. 802-811, 2012.

[7] R. Yang, S. Fan, Q. Liu et al., "Research of mine polymer reinforcement materials of low toxicity smoke," Guangdong Chemical Industry, vol. 43, no. 8, pp. 63-64, 2016.

[8] J. Zhao, "Research on PET used for mine reinforcement material of polyurethane," China Plastics Industry, vol. 38, pp. 144-146, 2010.

[9] H. Wu, D. Han, and H. Wu, "New research progress and application of the silicate modified grouting consolidation materials," Coal Science and Technology, vol. 43, pp. 29-31, 2015.

[10] S. Zhu, R. Xia, Y. Tang et al., "Influence of antistatic agent on the comprehensive performance of polyurethane grouting material for coal mine," New Chemical Materials, vol. 43, no. 5, pp. 232-236, 2015.

[11] C. Jia and B. Zheng, "The application of polymer double liquid chemical materials in the reinforcement of the large fault plugging water injection," Shandong Coal Science and Technology, vol. 23, no. 11, pp. 91-95, 2017.

[12] Z. Feng and H. Kang, "Development and application of new waterproof grouting materials of polyurethane," Chinese Journal of Geotechnical Engineering, vol. 32, no. 3, pp. 375$380,2010$.

[13] Y. Song and Q. Gao, "Mechanism of grouting for waterproof using organic material with high water content," Journal of Mining \& Safety Engineering, vol. 23, no. 3, pp. 320-323, 2006. 
[14] D. Guo, Z. Cheng, J. Yunqi et al., "Performance test of the composite polyurethane of water glass-nano-silica as grouting material," Modern Mining, vol. 23, no. 4, pp. 157-160, 2018.

[15] C. Jiang, J. Cao, H. Jiang et al., "Polyurethane-pre-groutinghigh pressure grouting sealing technology of coal seam gas pressure measurement," Coal Technology, vol. 33, no. 9, pp. 315-317, 2014.

[16] L. Zhang, G. Chang, B. Lin et al., "Application of new PD material in gas drainage and hole sealing," Coal Engineering, no. 1, pp. 43-45, 2013.

[17] L. Ning, Q. Zhao, Z. Xin et al., "A new type of polyurethane polyurea gas extraction sealing material," Modern Chemical Industry, vol. 35, no. 10, pp. 81-83, 2015.

[18] A. Li, Preparation and Study on Safety Performance of PreGrouting Material and Its Application in Coal Seam Gas Pressure Measurement Method, China University of Mining and Technology, Xuzhou, China, 2018.

[19] Y. Han, F. Zhang, and Z. Yang, "Analysis of stability of coalbed borehole wall," China Safety Science Journal, vol. 24, no. 6, pp. 80-85, 2014.

[20] L. Xu, Experiment Study on Method of Initial Gas Emission from Borehole for Outburst Prediction in Cross-Cut Coal Uncovering, China University of Mining and Technology, Xuzhou, China, 2015.

[21] X. Ding, Y. Ding, and S. Yu, "Incipient fracture of coal under one dimension gas seepage," Chinese Journal of Theoretical and Applied Mechanics, vol. 22, no. 2, pp. 154-162, 1990.

[22] Z. Wang, Y. Liang, and H. Jin, "Analysis of mechanics conditions for instability of outburst-preventing borehole," Journal of Mining and Safety Engineering, vol. 25, no. 4, pp. 444-448, 2008.

[23] Q Fan, Stability Analysis Pf Horizontal Directional Drilling Hole-Wall and Application in Engineering, Xi'an University of Science and Technology, Xi'an, China, 2010.

[24] C. Jiang and Q. Yu, The Spherical Shell Instability Mechanism and Prevention Technology of Coal and Gas Outburst, China University of Mining and Technology Press, Xuzhou, China, 1998.

[25] H. Li, G. Yin, J. Xu et al., Rock Fracture Mechanics, Chongqing University Press, Chongqing, China, 1988.

[26] Q. Deng, Y. Luan, and Y. Wang, "Coal and gas outburst simulation test," Safety in Coal Mines, vol. 11, pp. 5-10, 1989. 